\title{
Podoba Primoža Trubarja v slovenski esejistiki
}

\author{
Katja Bergles \\ Univerza v Mariboru, Filozofska fakulteta, Koroška cesta 160, \\ SLO-2000Maribor,katja.bergles@gmail.com
}

\begin{abstract}
Prispevek ponuja pregled nad izbranim esejističnim korpusom Ivana Cankarja, Tarasa Kermaunerja, Ferda Kozaka, Denisa Poniža, Ivana Prijatelja, Alojza Rebule in Jožeta Snoja. V njihovih besedilih sem iskala potrditev teze Ivana Prijatelja, ki pravi, da sta tako Primož Trubar kot slovenska reformacija odločilno sooblikovala zavest o nas samih in da je slovenska kultura ter $\mathrm{z}$ njo slovenska narodna bit nastajala $\mathrm{v}$ razmeroma tesnem in pozitivnem stiku z nemško kulturo.
\end{abstract}

This paper presents an overview of the selected essay corpus of Ivan Cankar, Taras Kermauner, Ferdo Kozak, Denis Poniž, Ivan Prijatelj, Alojz Rebula, and Jože Snoj. In their texts I attempted to find confirmation of the thesis of Ivan Prijatelj that the consciousness of our selves, and of the fact that Slovene culture and the Slovene national essence took shape in relatively close and positive connection with German culture, was decisively formed by Trubar and by the Slovene Reformation.

Ključne besede: Trubar, protestantizem, esejistika, Cankar

Key words: Trubar, Protestantism, the Essay, Cankar

0 Slovenska znanost o književnosti visoko ceni delo slovenskih protestantskih piscev - v smislu slovenskih literarnih začetkov, a tudi z vidika splošnega kulturnega pomena, ki so ga Primož Trubar, Jurij Dalmatin, Adam Bohorič in Sebastijan Krelj udejanjali z uvajanjem slovenščine v javno rabo. Pričakujemo lahko, da se tudi sočasna esejistika ni mogla prav dosti oddaljiti od vrednotenj Mirka Rupla, Franceta Kidriča, Ivana Grafenauerja in kasneje Jožeta Pogačnika ter Igorja Grdine. Kljub tej predpostavki pa je zaradi poudarjeno subjektivnega odnosa, prek katerega esejist svoje videnje vključuje v različne kontekstualne zveze, treba pogledati, kaj se je na tem področju v resnici dogajalo. Za to, da bi ugotovila, kako so posamezni pisci v preteklem stoletju videli kulturni 
pomen reformacije, sem izbrala korpus treh Cankarjevih predavanj ter šestih esejev priznanih slovenskih avtorjev: Tarasa Kermaunerja, Ferda Kozaka, Denisa Poniža, Ivana Prijatelja, Alojza Rebule in Jožeta Snoja. Izbrani teksti se obračajo k istim ali vsaj zelo podobnim vprašanjem, ta pa so: kje so začetki slovenske kulture, kdaj se je slovenstvo uzavestilo kot daljnosežni projekt, kako se je zamisel realizirala v stoletjih po reformaciji, kakšne so zveze med Primožem Trubarjem, drugimi protestantskimi pisci in slovensko književnostjo ter slovenskim jezikom itn. Gre za spise, ki potrjujejo moje izhodišče, da vidnejši slovenski ustvarjalci reformaciji in Trubarju priznavajo zelo pomembno vlogo pri postopnem oblikovanju Slovencev v narod. Naj navedeno na kratko utemeljim. Ivan Cankar je v svojih predavanjih Slovensko ljudstvo in slovenska kultura, Ob Trubarjevi štiristoletnici ter Trubar in Trubarjeve slavnosti v reformatorjevih prizadevanjih opažal začetek akcije, ki ni obetala le verske avtonomije, temveč tudi jezikovno in kulturno avtonomijo. Taras Kermauner v eseju Pomen slovenske književnost za slovenski narod razmišlja o Primožu Trubarju kot o začetniku »suverenizacije Slovencev v novodobnem kulturnem in družbenem pomenu « (Kermauner 1989: 216). Ferdo Kozak v eseju V temi Trubarjevo vrednost vidi predvsem $v$ nacionalnem smislu. Pravi, da je prva knjiga pomenila revolucijski prevrat $\mathrm{v}$ zavesti človeka, občutek manjvrednosti in podrejenosti nas je začel zapuščati, stopili smo na pot jasnih ciljev. Alojz Rebula v eseju Izviri slovenske duhovnosti loči med pojmoma slovenske kulture in slovenstva. Medtem ko nastanek prve vidi v tisočletnem postopnem razvoju, ki se je začel z Brižinskimi spomeniki, slovenstvo povezuje z nastankom zavesti o drugačnosti, ki je zagon dobila s Primožem Trubarjem. Esejist poseben pomen daje Trubarjevi odločitvi za slovenščino, za dejanje integrativnega značaja. Status začetnika kulture je Trubarju v svojih predavanjih Slovensko ljudstvo in slovenska kultura, Ob Trubarjevi štiristoletnici ter Trubar in Trubarjeve slavnosti jasno dodeljeval Ivan Cankar. Kot začetniku slovenske literature mu je priznal temeljni pomen v kulturnem smislu, podeljeval mu je vlogo pri prerodu vsega slovenstva. Nekatera stališča slovenskega modernista je kasneje v eseju Ivan Cankar in moralni problem(i) našega časa potrdil Denis Poniž. Jože Snoj pa je v prispevku Podvojena izročenost jeziku Trubarjevo pomembnost za narod videl v tem, da smo se Slovenci vse od Trubarja naprej zavedali svojega jezika in se mu nismo želeli več odreči. Najkompleksnejše je o pomenu slovenskih protestantov za kulturni in narodnostni razvoj Slovencev pisal Ivan Prijatelj v eseju O kulturnem pomenu slovenske reformacije. V njem sta zanimivi predvsem dve tezi, in sicer, da je slovenska reformacija odločilno sooblikovala zavest o nas samih ter da sta slovenska kultura in z njo povezana slovenska narodna bit nastajali $\mathrm{v}$ razmeroma tesnem in pozitivnem stiku $\mathrm{z}$ nemško kulturo oziroma $\mathrm{z}$ demokratičnimi pridobitvami sicer tujega in zato nevarnega, a vendarle koristnega sveta.

1 Kljub temu da se je Slovenec »naselil prvenstveno tja, kjer je našel že za kulturo pridobljeno zemljo, odprt, močno iztrebljen ali pa z gozdom le slabo porasel svet /.../« (Rebula 1987: 38), da »smo se tako rekoč usedli v prazno 
hišo, ki nam je ponudila sprejetje« (Rebula 1987: 39), je bil Trubar tisti, ki je naši kulturi dal ime. Vendar pa premik k vsesplošno kulturnemu narodu, če se za takšnega lahko imamo, ni bil nenaden. Ivan Prijatelj je v eseju O kulturnem pomenu slovenske reformacije ugotavljal, da v tistih časih kultura izven meja vere ni obstajala. Da ni bilo na začetku dvajsetega stoletja nič drugače in da se kulture še vedno ni primerno cenilo, je v svojem predavanju $O b$ Trubarjevi štiristoletnici pokazal tudi Ivan Cankar. Ostro je zavrnil hinavščino t. i. »narodnjakov«, ki v slavnostih ob raznih obletnicah vidijo le možnost za lastno promocijo, v resnici pa Prešernovega ali Trubarjevega dela sploh ne poznajo. V predavanju Slovensko ljudstvo in slovenska kultura ${ }^{1}$ je podobno zapisal, da so ljudje o Prešernu vedeli le to, da je popival, živel v divjem zakonu ter pisal ljubezenske pesmi (Cankar 1976: 164). S tem je poudaril, da se zaradi prevladujoče katoliško-moralistične optike slovenske umetnosti ni ocenjevalo po njenih literarno-estetskih komponentah, ampak predvsem skozi prizmo ozkih vzgojnih interesov katoliške cerkve.

Kot je na začetku prejšnjega stoletja poudaril Ivan Prijatelj, je katoliška cerkev nastala na temeljih razvalin rimske države, sicer v njenem okviru, a kot njeno nasprotje. Ideal in merilo vsega je postala Biblija, ki je zatajila razum in zmernost ter se obrnila k popolnemu asketizmu. Posledice teh previsoko zastavljenih idealov, ki so velikokrat nasprotovali naravnim nagnjenjem in nagonom, so se kazale v idejnem in moralnem razkroju Cerkve. Le-ta se je obrnila proti svojim prvotno postavljenim načelom, začela je bogateti in izkoriščati ljudstvo. Cankar v svojem predavanju Trubar in Trubarjeve slavnosti $\mathrm{k}$ temu dodaja še izkoriščanje ljudi s strani duhovne in posvetne gospode. Pravi, da so jih izželi do kosti in jih obsodili na še komaj človeško življenje (Cankar 1976: 191).

Razmere, ki so izzvale reformacijo, so bile izraz splošne prakse povsod po Evropi; vzbujale so neugodje in upor pri bolj razgledanih posameznikih, željnih prej duhovnih kot materialnih dobrin. Ivan Prijatelj je zelo neposredno zapisal, da je s kulturnega stališča reformacija pomenila klic po odpravi anahronizmov in laži ter podala zahtevo po upoštevanju lastnega individualnega mišljenja (Prijatelj 1908: 13).

Posebne spodbude, morda celo paradoksalno situacijo, ki je interes za novosti v cerkvenem življenju močno povečala, je predstavljal tudi odpor cerkvene in politične oblasti do reformacijskih prizadevanj. Ivan Prijatelj v svojem eseju $O$ kulturnem pomenu slovenske reformacije piše, da je le preganjana veroizpoved

${ }^{1}$ V govoru Slovensko ljudstvo in slovenska kultura iz leta 1907 je Ivan Cankar ugotavljal nasprotje med dejanskimi kulturnimi in posredno narodnostnimi potrebami Slovencev na eni strani ter prizadevanji takratnih politikov na drugi. Ob tem je problematiziral egoistične osebne in strankarske cilje. Pisec predavanja za tisk sam ni pripravil. Zaradi svojega sporočila, le-to je presegalo zgolj interese tržaškega delavstva, je bilo predavanje leta 1921 objavljeno v Domu in svetu.

Cankarjevo predavanje skupaj z intervjujem Matjaža Kmecla Smo pač mečkači že od $n e k d a j$, ki je bil objavljen leta 2008, posamezna esejistična razmišljanja dopolnjuje s stališči dveh pomembnih, za slovenstvo tako rekoč neobhodnih piscev. 
lahko ostala nepokvarjena. Skupaj z državo je Cerkev zmeraj znova iskali sredstva, s katerimi bi zatrli ali vsaj omejili nov nauk in preprečili njegovo širjenje med ljudmi. Lep dokaz za to so bili Trubarjevi umiki na Nemško, katerih posledica je bila, da je bila tiskana beseda pogosto edini stik med verniki in novim naukom. Kljub neugodnim razmeram in kljub temu da se protestantsko bogoslužje ni gojilo z ljudstvu privlačnimi ceremonijami, si je vendarle pridobilo dovolj privržencev. Simpatiziranje z reformacijo je bilo pravzaprav nekakšen »slovenski« upor, ki ga je Ivan Cankar v svojem govoru Slovensko ljudstvo in slovenska kultura $\mathrm{v}$ enaki meri kot Trubarjevo prizadevanje razumel v smislu kulturnega in političnega gibanja. Pomenil mu je željo po svobodi, svobodi kot pogoju kulturne rasti. V omenjenem predavanju je tako zatrdil, da sta si Trubar in Dalmatin postavila spomenik svojega slavnega dela s knjigo, puntarski kmetje pa so ga zapisali v kamnito zemljo s svojo krvjo (Cankar 1976: 167).

2 Reformacija je bistveno prenovila ne le takratno Cerkev, temveč tudi splošno mišljenje in zavedanje slovenskega ljudstva, prebudila zavest o lastni vrednosti ter Slovence prerodila v kulturen narod. Protestantizem je začel priznavati narodne posebnosti, zavračal je centralizem in iskal individualizem. Ivan Prijatelj je v eseju $O$ kulturnem pomenu slovenske reformacije zapisal, da smo mali narodi z reformacijo začeli šele živeti, in nadaljeval z ugotovitvijo, da protestanti niso le prebudili upora proti pokvarjenosti znotraj rimskokatoliške cerkve, izpostavili željo po svobodi, niso spodbudili samo védenje in zavedanje o vrednosti jezika, ampak je šlo preprosto za to, da so procesi 16. stoletja Slovence dejansko opozorili na njihovo individualnost, posebnost in vrednost. Ivan Prijatelj je prvi slovenski esejist, ki je jasno povedal, da je reduciranje Trubarjevega pomena zgolj na dogodke, povezane z versko-etično prenovo rimskokatoliške cerkve, nepošteno in zgodovinsko neutemeljeno. Njegovo stališče, da se je Primoža Trubarja, Jurija Dalmatina, Adama Bohoriča in Sebastijana Krelja prevečkrat prikazovalo izključno kot reformatorje in se jih sodilo samo z verskega oziroma protiverskega stališča, medtem ko je bila njihova kulturna vloga potisnjena $\mathrm{v}$ ozadje, je pomenilo odločilen premik v razumevanju reformacije. Tej oceni je potrebno dodati še že omenjena predavanja Slovensko ljudstvo in slovenska kultura, Ob Trubarjevi štiristoletnici ter Trubar in Trubarjeve slavnosti, $\mathrm{v}$ katerih je tudi Ivan Cankar Primožu Trubarju enoznačno pripisal pionirstvo na področju kulture in hkrati ugotovil, da gre za izjemnega človeka, katerega duhovnih dimenzij še vedno ni mogoče do konca izmeriti. Pri zadnjem je pisec gotovo ciljal na meščansko brezbrižnost, malomeščanski oportunizem in kapitalistično priseganje na zgolj ozko ekonomske interese. Tako je Ivan Cankar pravzaprav že pred Prijateljem opozoril, da se je v reformacijski dobi pokazalo prvo znamenje novo vzklile kulture, ki je pomenilo spremembo stanja zavesti in spodbudilo Slovenca, da se je odločil upreti svoji podrejeni vlogi. V novem gibanju je videl hrepenenje ljudstva po svobodi, verske reformatorje pa kot nosilce, buditelje in voditelje, ki so se v boju proti suženjstvu »poslužili orožja literature in tako napisali prvi dokument kulture slovenske (Cankar 1976: 166). V predavanju Trubar in Trubarjeve slavnosti je ob njegovi štiristoletnici celo 
zapisal, da Trubar ni bil le stvarnik slovenskega pisemskega jezika, ampak je bil celo eden največjih ljudi, »kar jih pozna tako prazna in tako žalostna zgodovina slovenskega naroda« (Cankar 1976: 191).

Kasnejša slovenska esejistika je sledila tem ocenam. Veliko piscev Trubarja razume kot začetnika slovenske literature in mu spoštljivo priznava temeljni pomen v kulturnem smislu. Cankar je v svojem predavanju z naslovom Trubar in Trubarjeve slavnosti zapisal, da je bil naš jezik v Trubarjevem času povzdignjen med književne jezike (Cankar 1976: 201). Tako za slovensko esejistiko njegov nauk ni pomenil le razčiščevanja situacije v Cerkvi, temveč tudi prerod vsega slovenstva, rojstvo zavesti o enakopravnosti našega jezika. Njegovo mnenje je skoraj devet desetletij kasneje potrdil Denis Poniž, in sicer v svojem prispevku $\mathrm{z}$ naslovom Ivan Cankar in moralni problem(i) našega časa. Z njima se strinja tudi Taras Kermauner, ki v eseju Pomen slovenske književnosti za slovenski narod iz leta 1989 pravi, da je Trubarjeva vloga začetnika kulture nesporna in da ti teksti kažejo bistvene poteze narodnega duha. Kermauner se v spisu zaveda, da bi se proces lahko obrnil tudi v smer ponemčevanja, a je prav zaradi Trubarjeve zavestne književno-jezikovne akcije dobil značaj in vsebino generatorja slovenskih kulturnih in narodnostnih ambicij. Kermaunerjev esej je eden ključnih dokumentov, ki opozarjajo, da se je slovenska narodna bit konceptualizirala zavestno in suvereno. Ferdo Kozak je v eseju $V$ temi leta 1971 zapisal, da je Trubar s svojim knjižnim prvencem Slovence spodbudil h kolektivni rasti. Avtor je prepričan, da je bila pred Trubarjem le »tema« in da je bil slovenski protestant prinašalec luči v našo kulturo. Narodotvorni in kulturni pomen Trubarju priznavata tudi Alojz Rebula in Jože Snoj. Prvi v eseju Izviri slovenske duhovnosti iz 1987. leta v naši siceršnji politični nepomembnosti in malopoteznosti ugotavlja izjemno daljnosežnost protestantovega predvsem jezikovno-kulturnega koncepta; Jože Snoj pa leto kasneje v prispevku Podvojena izročenost jeziku zapiše, da se slovenski pesniki in pisatelji od Trubarja naprej niso več želeli odreči pisanju v slovenskem jeziku. Slovenski jezik je po mnenju obeh navedenih avtorjev ravno v času reformacije prvič dobil veljavo, zalet in pogoje za enakopravnost drugim evropskim jezikom, s tem pa so bili ustvarjen ključni pogoji za to, da se začne proces integracije, ki bo razpršen občutek pripadnosti ljudstvu prestrukturiral v celovito zavest naroda. Rebula je v eseju tako zaneseno zapisal, da lahko v polnosti duše naroda živimo le, če v polnosti živimo jezik (Rebula 1987: 36-37).

Reformacija je pomenila rojstvo prve knjige, zato ni presenetljivo, da ključne misli v eseju $V$ temi Ferda Kozaka ciljajo na totalno marginalno pozicijo Slovencev v 16. stoletju (Kozak 1971: 203). K navedenemu lahko dodamo še v reviji 7 dni objavljen intervju Smo pač mečkači že od nekdaj (2008) ${ }^{2}$ enega bolj znanih slovenskih esejistov Matjaža Kmecla, v katerem je zatrdil, da šele od Trubarja naprej obstajamo oziroma se šele z reformacijo začenja novodobna slovenska zgodovina, in sicer zato, ker je pisec prve knjige v slovenščini spoznal,

\footnotetext{
${ }^{2}$ Glej opombo 1.
} 
da je slovenski svet bogastvo, ki se ga ne sme zavreči. Krog visokih ocen o slovenski reformaciji je mogoče skleniti z ugotovitvijo, da so izbrani slovenski esejisti 20. stoletja ob različnih priložnostih utemeljeno ugotovili, da bi bil brez prodornih in preroških misli slovenskih protestantov s Primož Trubarjem na čelu v zgodovini Slovencev opazen primanjkljaj.

$3 \mathrm{~V}$ eseju $O$ kulturnem pomenu slovenske reformacije Ivan Prijatelj med drugim tudi zapiše, da je v preteklosti katoliška kritika pogosto poudarjala kvaren vpliv protestantizma, ki naj bi Slovencem omogočil nevaren stik z nemštvom. Sam zagovarja nasprotno tezo in nemštvu priznava spodbuden vpliv na naš razvoj. Ta izzivalna, v času, ko je bila zapisana, morda celo zelo smela trditev, ni mogla biti posledica sumljivih narodnoetičnih presoj, saj vemo, da je Ivan Prijatelj svojo profesionalno kariero namesto na stari Karlovi univerzi v Pragi, kjer so mu ponujali mesto profesorja ruske književnosti, začel na novoustanovljeni slovenski univerzi v Ljubljani, s čimer je svojo naklonjenost domovini in slovenstvu izpričal na najboljši možni način. Prijateljevo stališče pa je bilo tudi drugače skladno z dejanskim stanjem in posledica temeljitega študija virov ter doslednega upoštevanja zgodovinske dinamike. Očitati Trubarju učenja pri sosedih ni na mestu, saj je naravno, da se človek zgleduje tam, kjer to lahko stori. Tako so tudi Nemci iskali spodbude v drugih kulturnih okoljih. Esejist je prepričan, da je treba neutemeljene očitke o škodljivem nemškem vplivu zavreči, saj je reformacija ravno prek germanskega sveta k nam vpeljala nov duhovni tok, katerega vsebina je bila demokratičnost. Enako misel najdemo tudi $\mathrm{v}$ prispevku z naslovom Izviri slovenske duhovnosti, v katerem Alojz Rebula zagotovi, da je reformacija v opazni meri tudi po nemški zaslugi Slovencem prinesla knjigo in s tem Evropo Gutenberga, Erazma Rotterdamskega ter Martina Lutra in nas tako usodno zaznamovala. Esejist celo zapiše, da za Štrekljevimi Slovenskimi narodnimi pesmimi, za Pleteršnikovim Nemško-slovenskim slovarjem in Doklerjevim Grško-slovenskim slovarjem stojita nemška resnobnost in organizacijska temeljitost (Rebula 1987: 41). O zmeraj občutljivem odnosu slovenstvo - nemštvo v 16. stoletju je pisal tudi Taras Kermauner v eseju Pomen slovenske književnost za slovenski narod in poudaril, da je ob začetkih formiranja slovenske zavesti nedvomno obstajala tudi resna nevarnost ponemčenja, a da se slednja preprosto ni zgodila ter je bila za to pot očitno prava.

Povedano lahko zaključimo s Prijateljevimi besedami:

Res je, da so pričeli z osvoboditvijo individua od rimske univerzalnosti Nemci, a ravnotako je res, da tega niso izvršili samo v svoje nacionalne namene. Bili so takrat Nemci /.../ nositelji splošnokulturne nove, mlade ideje, ki je postala obča posest in podlaga vse nove kulture in njenega glavnega decentralizujočega in zato podrobno delujočega činitelja - individualizma (Prijatelj 1908: 52).

4 Za slovensko esejistiko obravnavanega obdobja je torej neovrgljivo dejstvo, da je reformacija položila trdne temelje naši literaturi, naši kulturi, kljub temu da se sama ni obdržala. Že Ivan Prijatelj priča, da lahko dodaten dokaz za 
tako trditev najdemo v dejstvu, da sta se v času protireformacije slovensko izobraževanje in napredek ustavila za dve desetletji. Protestantizem je bil nasilno zadušen, sežgali so njegovo dediščino in narod ponovno izključili iz kulture. Vendar pa nasilna protireformacija, ki jo Matjaž Kmecl v omenjenem intervjuju imenuje kar »surova, barbarska prekinitev nečesa, kar se je razvijalo Slovencem v prid« (Kmecl 2008: 15), reformacijske dediščine vseeno ni popolnoma izničila. Ostala je zavest o in želja po narodnem jeziku, ohranili so tudi Dalmatinov prevod Biblije. Z njim se je ohranjalo protestantsko izročilo, povzročil pa je tudi nesporen napredek slovenskega jezika. Slovenski protestanti so s svojim delom uzavestili slovenstvo, s tem afirmirali slovenščino in omogočili postopen razvoj posvetne kulture, versko življenje pa so organizirali v okviru slovenske cerkvene organizacije. Zaradi teh daljnosežnih narodnih odločitev imajo reformacija in njeni predstavniki tudi danes posebno mesto $\mathrm{v}$ slovenskem zgodovinskem spominu.

Po premisleku esejističnega korpusa, ki je razpravljal o različnih vidikih slovenstva v kontekstu reformacije, lahko zaključim:

1. Posebno mesto iz razumljivih razlogov zaseda Primož Trubar.

2. Književnost in slovenščina sta $\mathrm{v}$ veliki meri nadomestilo manjkajočim, a v nacionalnem smislu zelo pomembnim institucijam.

3. Narodni diskurz je v glavnem utemeljen na kulturi, literaturi in jeziku ter izpostavlja razvojno pomembnost reformacijskega gibanja.

4. Tako starejši kot mlajši esejisti, pisci različnih nazorskih izhodišč, zamejski ustvarjalci in domači avtorji so si edini, da bi bil brez Trubarjevih jasnih in odmevnih jezikovnih in kulturnih stališč ter brez njegovega slovstvenega dela v zgodovini Slovencev opazen primanjkljaj.

\section{LITERATURA}

Ivan CANKAR, 1976: Slovensko ljudstvo in slovenska kultura. Zbrano delo. Petindvajseta knjiga. Ljubljana: Državna založba Slovenije. 158-183.

Ivan CANKAR, 1976: [Ob Trubarjevi štiristoletnici]. Zbrano delo. Petindvajseta knjiga. Ljubljana: Državna založba Slovenije. 188-190.

Ivan CANKAR, 1976: Trubar in Trubarjeve slavnosti. Zbrano delo. Petindvajseta knjiga. Ljubljana: Državna založba Slovenije. 191-206.

Taras KERMAUNER, 1989: Pomen slovenske književnost za slovenski narod. Dom in svet. Zbornik 1989. Maribor: Slomškova založba. 214-225.

Matjaž KMECL, 2008: Smo pač mečkači že od nekdaj. 7 dni, letnik 57. 14-16.

Ferdo KOZAK, 1971: V temi. Izbrano delo. Ljubljana: Mladinska knjiga.

Denis PONIŽ, 1993: Ivan Cankar in moralni problem(i) našega časa. Črtomirovo slovenstvo. Ljubljana: Cankarjeva založba. 47-68.

Ivan PRIJATELJ, 1908: O kulturnem pomenu reformacije. Ljubljana: L. Schwentner. 
Alojz REBULA, 1987: Izviri slovenske duhovnosti. Na pragu tretjega tisočletja. Celje: Mohorjeva družba. 29-42

Jože SNOJ, 1988: Podvojena izročenost jeziku. Nova revija, št. 77. 1393-1397.

\section{PRIMOŽ TRUBAR'S IMAGE IN SLOVENE ESSAYISTIC}

The purpose of my paper was to trace the significance of Trubar's cultural work in the Slovene essay of the $20^{\text {th }}$ century. As we know from the earliest medieval written record, Slovene literary studies treasured the work of the Slovene Protestant writers Primož Trubar, Jurij Dalmatin, Adam Bohorič and Sebastijan Krelj till the beginning of the $19^{\text {th }}$ century. We can presume that contemporary studies of the essay would not disagree with assessments by Mirko Rupel, France Kidrič, Ivan Grafenauer, and later Jože Pogačnik and Igor Grdina. However, because the study of the essay is more subjective and in that sense also more provocative than literary history, my intention was to find out what was really going on in this domain. For this purpose I selected a corpus of seven Slovene writers: Ivan Cankar, Taras Kermauner, Ferdo Kozak, Denis Poniž, Ivan Prijatelj, Alojz Rebula, and Jože Snoj. Their works are interesting because each of them in his own way appeals to the same question: to the matter of Slovene culture from the historical point of view. In the selected writings I tried to confirm the thesis by Ivan Prijatelj which states that the Slovene Reformation as well as Trubar significantly co-formed Slovene self-concepts. Furthermore, Slovene culture and the Slovene national essence took shape in relatively close and positive contact with German culture, or with democratic acquisitions from an otherwise foreign, and thus threatening, but nevertheless useful world. After consideration of this corpus of essays reflecting varied viewpoints on Slovene culture and language in the framework of the Reformation, we can reach the following conclusions:

1. For judicious reasons, the important place is reserved for Primož Trubar.

2. To a great extent Slovene literature and language are a substitute for institutions that are non-existent but, in the national sense, of great importance.

3. The national discourse is mostly founded on culture, literature, and language and is receptive to the developmental importance of the Reformation movements.

4. Older and younger essayists, writers of varying principles, foreign writers, and national authors are of the same opinion: without Trubar's clear and audible linguistic and cultural viewpoints and without his literary work, there would be a discernible deficiency in the history of the Slovene nation. 